Check for updates

Cite this: Mater. Adv., 2021, 2, 4677

Received 5th February 2021, Accepted 21st May 2021

DOI: $10.1039 / \mathrm{d} 1 \mathrm{ma} 00111 \mathrm{f}$

rsc.li/materials-advances

\section{Self-healing ferroelastic metal-organic framework sensing guests, pressure and chemical environment $\dagger$}

\begin{abstract}
Aleksandra Pótrolniczak (D) and Andrzej Katrusiak (D)*
Strong strain shuttering ferroelastic crystals that self-heal after releasing the strain have been revealed for a new metal-organic framework $[C d(B D C)(A Z P Y)]_{n}\left(B D C=\right.$ terephthalic acid; $A Z P Y=4,4^{\prime}$ azobispyridine), with the $\mathrm{Cd}(\Perp)$ cation hepta-coordinated. It has been obtained in the form of single crystals without and with guests, acetonitrile or DMF (dimethylformamide). This pleochroic porous complex, hereafter referred to as AMU3, is built of two interwoven frameworks with the planar AZPY linkers $\left(C_{2 h}\right.$ symmetric) orientationally disordered on the $D_{2 h}$ sites. The disorder of AZPY linkers persists down to $100 \mathrm{~K}$ at least, but it is eliminated by high pressure. The onset of AZPY ordering in the $0.2-0.9 \mathrm{GPa}$ range depends both on the guest and on the hydrostatic fluid. The mechanism of AMU3 ferroelasticity involves the AZPY disordering in prototypic orthorhombic phase $\alpha$ of space-group Cmce. The AZPY ordering reduces the symmetry of phase $\beta$ to monoclinic subgroup $P 2_{1} / n$. The shear strain in the bulk of ferroelastic orientational-state domains is accommodated by the tilts and conformational changes of the ordered AZPY linkers, while along the boundaries between domains the $\mathrm{Cd}-\mathrm{N}$ bonds break. On releasing the pressure the $\mathrm{Cd}-\mathrm{N}$ bonds are restored and the signs of the cracks disappear.
\end{abstract}

\section{Introduction}

Rational design and synthesis of functional metal-organic frameworks (MOFs) requires a palette of accessories in the form of chemical components of predictable features and transitions in various thermodynamic conditions. The key factors are the topological architectures of MOFs and a selection of appropriate building blocks. ${ }^{1-3}$ Usually, frameworks of desired topologies can be obtained by selecting the size and valence of cations, as well as geometrically defined building blocks of organic linkers. ${ }^{4}$ Such materials are often thermally and mechanically stable even after removing the guest molecules. $^{5-9}$ These features are found in ligands commonly used as organic building blocks, for example rigid benzene di-, tri-, and tetra-carboxylates, and azolate-based ligands, as well as

Department of Materials Chemistry, Faculty of Chemistry,

Adam Mickiewicz University, Uniwersytetu Poznańskiego 8, 61-614, Poznan, Poland. E-mail:katran@amu.edu.pl

$\dagger$ Electronic supplementary information (ESI) available: Experimental details, Raman spectra, results of quantum-mechanical calculations, compressibility and thermal expansion analysis, framework topology scheme, survey on the CCDC database concerning the AZPY linker, void volume changes, pleochroic effect, compressibility calculations, and detailed crystallographic data; supplementary movie: self-healing of AMU3 (mp4); CCDC 2046185-2046192, 20461982046205, 2046207-2046212, 2046216-2046220 and 2046409. For ESI and crystallographic data in CIF or other electronic format see DOI: 10.1039/d1ma00111f their derivatives. Also flexible molecules, such as 4,4'azo(bis)pyridine (AZPY, Fig. 1), are known for effective bridging coordination capabilities. ${ }^{10-12}$ The AZPY linkers often exhibit disorder, most often in two positions due to the strong conjunction of the alternative $\pi$-electron bonds across the molecule and the flat pyridyl moieties. ${ }^{13,14}$ In azopyridine there are two types of coordination sites involving the nitrogen atoms: those in pyridyl moieties and those in the azo bridge. The pyridyl ring has been employed in a variety of coordination geometries. Depending on the metal center, it is possible to construct a wide range of compounds, such as multinuclear complexes (in the forms of dimers, squares, and rectangles), molecular frameworks (for instance brick-wall, herringbone, or wave-like motifs), and coordination polymers. The coordination mode involving the azo bridge is less common. A variety of MOFs containing AZPY have been prepared and characterized. ${ }^{15-18}$ In such sorbent materials, the primary sites of gas adsorption in the pores are very important. As a result of free basic centers ('azo' nitrogens) in the AZPY molecule, these nitrogen atoms can serve as the primary adsorbers. Moreover, the AZPY linkers can undergo conformational changes, activated by light. ${ }^{19-23}$

Owing to their internal structure, MOFs are highly elastic and pressure-sensitive. ${ }^{24-29}$ These features can be further increased by flexible linkers and large voids. Pressure is a thermodynamic variable that affects the volume of crystals more efficiently than it is done by temperature. ${ }^{30-32}$ Under 


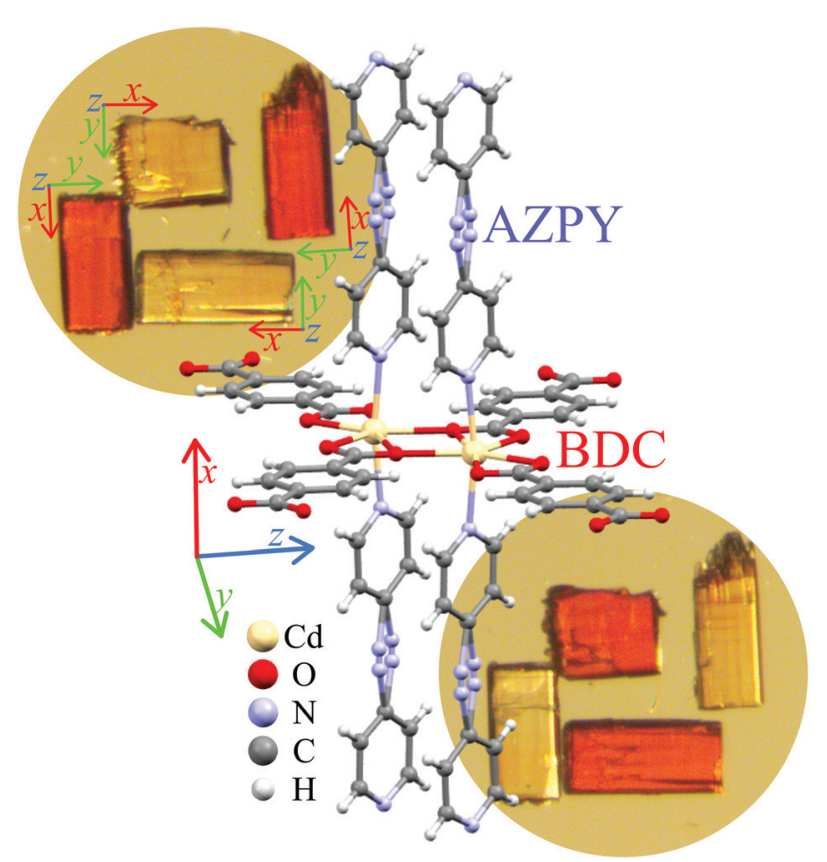

Fig. 1 The double Cd(॥) centre coordinated by AZPY and BDC linkers in AMU3 under normal conditions, including both sites of disordered AZPY linkers. In the first inset, several single-crystal AMU3 samples are aligned parallel and perpendicular to the polarized light, then rotated by $90^{\circ}$ for the second inset.

high pressure all (one-phase) materials contract in volume. ${ }^{33,34}$ This compression can be isotropic or anisotropic. The compression of most materials is positive in all directions; however occasionally the negative linear compression ${ }^{35-39}$ and negative area ${ }^{40-43}$ compression are observed. Anomalous compression can be caused by an uptake of guest $\mathrm{t}^{29,44-48}$ or its release, ${ }^{49-51}$ as well as solid-state phase transitions ${ }^{52,53}$ and chemical reactions. ${ }^{54-61}$ The most typical pressure-induced changes affect the voids, which are most relevant to sorption and elastic properties of MOFs. Many crystals undergoing phase transitions induced by hydrostatic pressure, or when subjected to none uniform stress, fracture and even break into pieces, which disqualifies their application or significantly limits the scope and time of their performance. There are also materials capable of self-healing their fractures, ${ }^{62,63}$ which is particularly needed in the active sensor parts. ${ }^{64-66}$

Here we report a new MOF, Cd(BDC)(AZPY), abbreviated as AMU3, synthesized of $4,4^{\prime}$-azopyridine and terephthalic acid (1,4-benzenedicarboxylic acid $=\mathrm{BDC})$ with $\mathrm{Cd}\left(\mathrm{NO}_{3}\right)_{2} \cdot 4 \mathrm{H}_{2} \mathrm{O}$, and solvent guest molecules. We have performed the pore activation process of AMU3 $\cdot \mathrm{DMF}$ (DMF = dimethylformamide) leading to guest-free AMU3 that when soaked with acetonitrile (MeCN) yielded AMU3.MeCN. We found that all these compounds are ferroelastic, and that their critical pressure and orientationstates strongly depend on the exchangeable guests. The exchange of guests provides a convenient method for tuning the ferroelastic properties, required for the materials used in chemo-mechanic transducers and various sensor applications. Under pressure the AMU3 crystals become fractured, but they exhibit a self-healing property in the prototypic phase.

\section{Experimental}

We have synthesized single-crystals of AMU3 by a slowdiffusion technique. In this method the substrates are dissolved in low- and high-density solvents and then placed one above another in a test tube. The speed of diffusion can be controlled by introducing an intermediate layer, usually of a mixture of pure solvents $(1: 1 \mathrm{vol}$.). Then the test tube is tightly closed. In this way, within 8 days orange elongated block AMU3 crystals are formed. After removing from the solvent, they are stable in air. Detailed information about the synthesis is presented in the ESI. $\dagger$

\section{Pore activation}

The applications for gas storage or gas-phase catalysis are scalable with large internal surface areas. In some MOFs the pores are blocked by molecules of solvents or other substances used for synthesis. Some of the frameworks collapse during the pore activation process, i.e. the removal of guest molecules. The most effective and general strategies for removing guest molecules are (i) conventional heating and exposure to vacuum; (ii) solvent exchange; (iii) supercritical $\mathrm{CO}_{2}\left(\mathrm{scCO}_{2}\right)$ processing; (iv) freeze-drying; and (v) chemical treatment. ${ }^{67}$

For activating the pores in AMU3 we chose the methods of (ii) solvent exchange and (iv) $\mathrm{scCO}_{2}$ processing. The $\mathrm{Cd}(\mathrm{BDC})(\mathrm{AZPY})$. DMF crystals have been immersed in chloroform and left for 3 days. The subsequent single-crystal diffraction measurements detected no guest molecules in the pores. During the pore activation, the quality of single-crystals decreased, which was manifested by a lower resolution of the diffraction data and broader reflections. After immersing the activated crystals in acetonitrile, its molecules penetrated into the pores and the quality of single-crystals improved. In the case of $\mathrm{scCO}_{2}$ processing, we have also obtained the guest-free structure, but mainly in the form of fine powder, naturally appearing green in the scattered light, which is the complement of deep orange colour of the light transmitted through the crystals. A similar change between the complementing deep-orange and green shades occurs between high-quality single crystals and the damaged samples (Fig. 2).

\section{Non-ambient X-ray diffraction}

We performed three series of high-pressure studies, each for the AMU3 crystal with different guest molecules in the pores and for different pressure-transmitting media (PTM). AMU3.DMF was compressed in a 16:3:1 (vol.) mixture of methanol: ethanol: water (MEW) and in glycerin, assuring the hydrostatic conditions up to $10.5 \mathrm{GPa}$ and $\sim 3.5 \mathrm{GPa}$, respectively. ${ }^{68}$ We observed a monotonic compression of AMU3.DMF up to $0.4 \mathrm{GPa}$, when a phase transition changed the crystal symmetry from orthorhombic space group Cmce to monoclinic space group $P 2_{1} / n$.

High-pressure experiments on AMU3 were performed in a Merrill-Bassett diamond anvil cell (DAC) ${ }^{69}$ modified by mounting the diamond anvils directly onto the steel supports with conical windows. The pressure in the DAC was calibrated by the ruby-fluorescence method with a photon control spectrometer, 


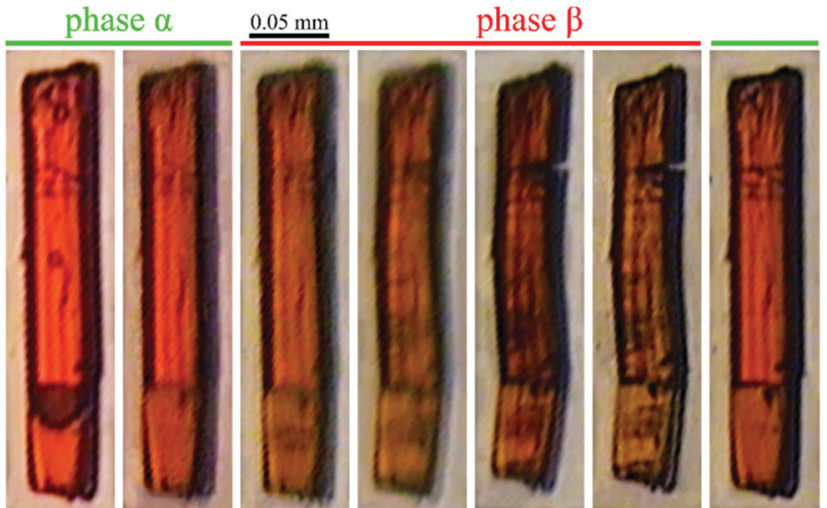

Fig. 2 AMU3.DMF crystal compressed and decompressed in methanol: ethanol: water mixture used as the hydrostatic medium. The green shade of the sample in phase $\beta$ is the light scattered on microfractures. The crystal axes in phase $\alpha$ are $[z]$ along the viewing direction; [y] horizontal and $[x]$ vertical.

affording the accuracy of $0.03 \mathrm{GPa}^{70,71}$ The gaskets were made of a $0.3 \mathrm{~mm}$ thick tungsten foil with spark-eroded holes of $0.5 \mathrm{~mm}$ in diameter. The X-ray diffraction data were measured on an Xcalibur EOS-CCD diffractometer with Mo $\mathrm{K} \alpha$ radiation $(\lambda=0.71073 \AA)$. The DAC was centered by the gasket-shadow method. ${ }^{72}$ The collected data were preliminarily reduced with the CrysAlisPro suite, version 171.38.46. ${ }^{73}$ OLEX2 was used. ${ }^{74}$ The structure was solved by direct methods with SHELXS and least-squares refined with SHELXL. ${ }^{75,76}$

The ambient-pressure structure was the starting model for the refinements of low-temperature and high-pressure structures. In high-pressure experiments the DAC absorption corrections and gasket shadowing were calculated by the program REDSHABS..$^{77,78}$ The low-temperature data were measured for the single-crystal mounted on a microloop on an Xcalibur EOSCCD diffractometer equipped with a gas-flow Oxford Cryostream attachment between 100 and $297 \mathrm{~K}$ in $40 \mathrm{~K}$ steps. All non- $\mathrm{H}$ atoms were refined with anisotropic thermal parameters. $\mathrm{H}$ atoms were located in the difference Fourier map and from the molecular geometry. The final crystal data are summarized in Table 1 ( $c f$. Tables S7-S10, ESI $\dagger$ ).

\section{Results and discussion}

The AMU3 crystal is built of two interwoven frameworks Cd(BDC)(AZPY), as illustrated in Fig. 3. In phase $\alpha$ the CdBDC (a)
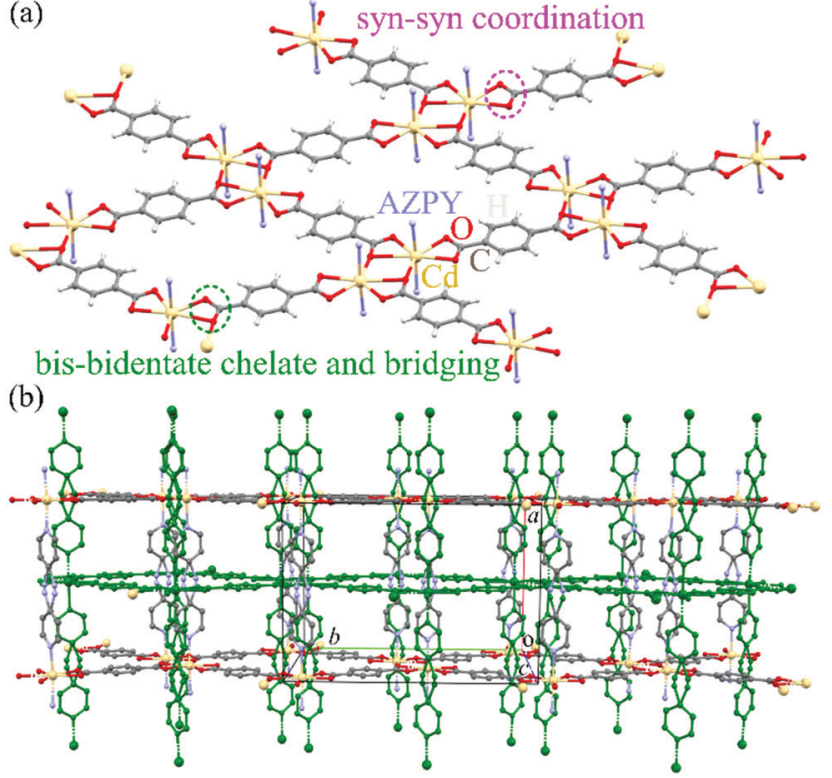

Fig. 3 (a) One CdBDC sheet, with added $\mathrm{N}$-atoms of AZPY linkers, extending along crystal plane (100); and (b) autostereogram of two interwoven frameworks, one coloured green, with AZPY linkers penetrating through the holes of two CdBDC sheets of another framework shown in yellow (Cd), grey (C), red $(\mathrm{O})$ and blue $(\mathrm{N})$. The DMF molecules and $\mathrm{H}$ atoms are skipped for clarity.

sheets are perfectly planar, as they are located on mirror planes perpendicular to the crystal [100] direction. In these sheets there are large holes inside the rings of four BDC anions coordinating $\mathrm{Cd}$ cations. The $\mathrm{Cd}$ cations are present in double-core tandem arrangement coordinated by four BDC anions, all within the planar sheet. On both sides of the CdBDC sheets, each Cd cation forms two other coordination bonds to AZPY molecules aligned parallel to direction [100]. Each CdBDC sheet is connected with next CdBDC sheets by the AZPY linkers, which on both sides penetrate through the rings of the closest CdBDC sheets belonging to the other framework.

\section{Lattice strain}

At ambient pressure the lattice of interwoven Cd(BDC)(AZPY) frameworks is orthorhombic, because the disordered AZPY molecules in the planar conformation are perpendicular to the CdBDC sheets (Fig. 3 and Fig. S5, ESI $\dagger$ ). The disordered AZPY molecules acquire the average $D_{2 \mathrm{~h}}$ symmetry, which is higher compared to the $C_{2 \mathrm{~h}}$ symmetry of the ordered molecule

Table 1 Selected crystallographic data of AMU3 phases $\alpha$ and $\beta$ compressed in methanol : ethanol : water (MEW, 16:3:1 vol.) mixture and glycerin (Gly)

\begin{tabular}{|c|c|c|c|c|c|c|c|c|c|c|c|}
\hline Phase & & $\alpha$ & $\alpha$ & $\alpha$ & $\beta$ & $\beta$ & $\beta$ & $\alpha$ & $\beta$ & $\alpha$ & $\beta$ \\
\hline Guest: & & $\mathrm{DMF}$ & MeCN & DMF & DMF & $\mathrm{DMF}$ & DMF & DMF & DMF & $\mathrm{MeCN}$ & MeCN \\
\hline \multirow[t]{3}{*}{ Unit-cell: } & $a(\AA)$ & $13.7238(4)$ & $13.6976(4)$ & $13.643(3)$ & $12.162(3)$ & $11.996(4)$ & $11.362(6)$ & $13.729(2)$ & $12.241(12)$ & 13.6195(11) & $12.372(3)$ \\
\hline & $b(\AA)$ & $20.7039(6)$ & $20.7250(7)$ & $20.739(3)$ & $13.928(18)$ & $13.77(3)$ & $13.31(3)$ & $20.856(4)$ & $13.970(11)$ & $20.7923(17)$ & $14.15(3)$ \\
\hline & $c(\AA)$ & $14.7091(4)$ & 14.6495(5) & $14.20(2)$ & $12.574(3)$ & $12.629(4)$ & $13.269(8)$ & $14.403(2)$ & $12.627(11)$ & $14.241(15)$ & $12.433(4)$ \\
\hline$Z / Z^{\prime}$ & & $8 / 0.5$ & $8 / 0.5$ & $8 / 0.5$ & $4 / 1$ & $4 / 1$ & $4 / 1$ & $8 / 0.5$ & $4 / 1$ & $8 / 0.5$ & $4 / 1$ \\
\hline
\end{tabular}


in the planar conformation. The ordered AZPY molecules in their energetically optimized conformation are skew, as the diazo-bridge shifts the axes of the pyridyls aside by $2.8 \AA$, which would induce a shear displacement of the sheets along the crystal axis $y_{0}$ (index 'o' indicates the orthorhombic phase $\alpha$ ). No such ferroelastic strain and no ordering of the AZPY linkers was observed on cooling the crystals down to $100 \mathrm{~K}$. At such low temperatures the dynamic disorder of either the diazo-bridge or all of the AZPY molecule is highly unlikely. The dynamic disorder of the azo-bridge would imply either quick rotations of all AZPY molecules (their conformation fixed planar) along their longest axis or a pedal-like movement of the pyridyls, which would require overcoming the potential-energy barrier between favoured planar conformations. Thus it is plausible that in the AMU3 phase $\alpha$ the static disorder of the AZPY linkers is present not only at low temperatures but also above room temperature. Therefore we have studied the AMU3 crystals under high hydrostatic pressure, which eliminates the disorder primarily through the volume reduction, and not through the temperature-controlled energy of vibrations. Indeed, at high pressure an onset of ordering of AZPY molecules induces the phase transition to monoclinic phase $\beta$. The phase transition occurs at the critical pressure $\left(p_{c}\right)$, which depends on the guest molecules and hydrostatic medium (Fig. 4).

Our X-ray diffraction structural determinations show that at $p_{\mathrm{c}}$ the AZPY linkers become ordered and their conformation changes from planar to twisted - the inclination of the pyridine rings increases with pressure: at $1 \mathrm{GPa}$ they are inclined by $2.02^{\circ}$ (between the average planes of pyridine rings $\mathrm{C} 2^{\prime} \mathrm{C}^{\prime} \mathrm{C}^{\prime}$ $\mathrm{C}^{\prime} \mathrm{C}^{\prime} \mathrm{N}^{\prime} \mathrm{N} 2^{\prime}$ and $\mathrm{C} 2^{\prime \prime} \mathrm{C}^{\prime \prime} \mathrm{C}^{\prime \prime} \mathrm{C}^{\prime \prime} \mathrm{C}^{\prime \prime} \mathrm{N} 1^{\prime \prime} \mathrm{N} 2^{\prime \prime}$, as indicated in Fig. 5) and at $3.66 \mathrm{GPa}$ this inclination increases to $30.76^{\circ}$ (Fig. 5). Thus the flexibility of the AZPY linkers is connected with the ferroelastic properties of the AMU3 crystal. Its prototypic phase $\alpha$ is associated with the AZPY linkers disordered,

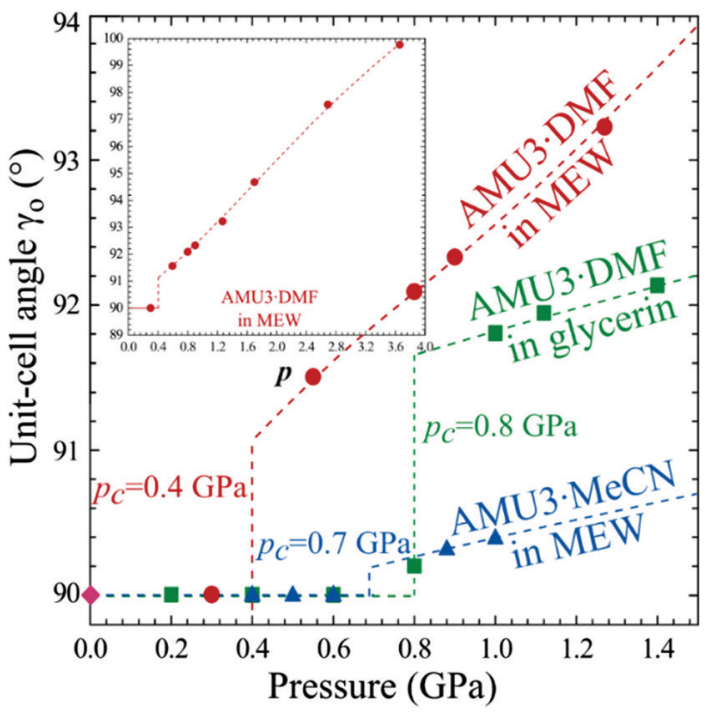

Fig. 4 Monoclinic strain in AMU3.DMF and AMU3.MeCN as a function of pressure. The inset extends the pressure range for AMU3.DMF compressed in methanol : ethanol: water (MEW, 16:3:1 vol.) mixture. (a)

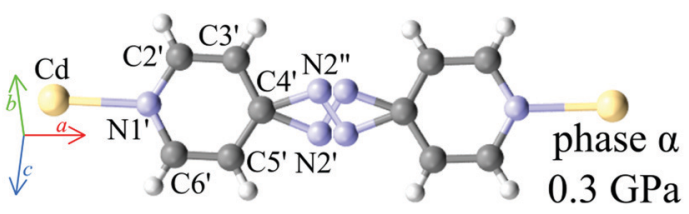

(b)

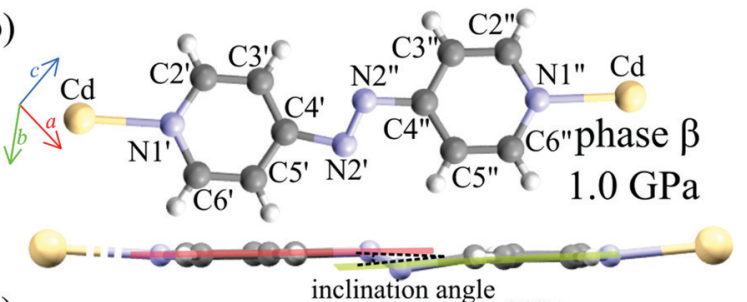

(c)

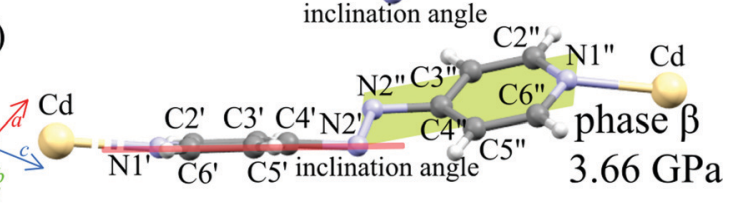

Fig. 5 The AZPY linker in $\mathrm{Cd}(\mathrm{BDC})(\mathrm{AZPY})$ : (a) disordered in phase $\alpha$; (b) ordered and somewhat distorted from coplanarity in phase $\beta$ (viewed perpendicular and parallel to the pyridyl rings); and (c) ordered-twisted at $3.66 \mathrm{GPa}$.

while the shear strain of orientational states in phase $\beta$ is regulated by the tilts of ordered AZPY linkers and their conformation.

The transition between phases $\alpha$ and $\beta$ can be described by the order parameter $\eta$ connected with the ordering of the AZPY molecules:

$$
\eta=\left|\operatorname{SOF}\left(\mathrm{N}_{2}^{\prime}\right)-\operatorname{SOF}\left(\mathrm{N}_{2}^{\prime \prime}\right)\right|,
$$

where $\mathrm{N}_{2}^{\prime}$ denotes azo group $\mathrm{N} 2^{\prime}=\mathrm{N} 2_{\mathrm{A}}^{\prime \prime}$, and $\mathrm{N}_{2}^{\prime \prime}$ is $\mathrm{N} 2^{\prime \prime}=\mathrm{N} 2_{\mathrm{A}}^{\prime}$ (subscript ' $\mathrm{A}$ ' indicates the symmetry operation through the mirror plane perpendicular to crystal direction [100]), $\operatorname{SOF}\left(\mathrm{N}_{2}^{\prime}\right)$ and $\operatorname{SOF}\left(\mathrm{N}_{2}^{\prime \prime}\right)$ are the site occupation factors of the disordered azo groups ( $c f$. Fig. 5 for atomic labels $\mathrm{N}^{\prime}, \mathrm{N} 2^{\prime \prime}$ and their disordered sites). In phase $\alpha$ the SOF values are equal to 0.5 , so the order parameter $\eta=0$, and for phase $\beta$ the ordered azo groups give $\eta=1$.

The Bravais lattice $C$ of phase $\alpha$ is orthorhombic, but in phase $\beta$ it becomes monoclinic $P$, as illustrated in Fig. 6. For describing the shear strain of the lattice we have chosen the $\gamma_{\mathrm{o}}$ angle of the unit cell in phase $\alpha$ (subscript 'o' refers to orthorhombic phase $\alpha$, 'm' to monoclinic phase $\beta$ ). The unitcell vectors between phases $\alpha\left(a_{\mathrm{o}}, b_{\mathrm{o}}, c_{\mathrm{o}}\right)$ and $\beta\left(a_{\mathrm{m}}, b_{\mathrm{m}}, c_{\mathrm{m}}\right)$ are transformed through matrices:

$$
\left(\begin{array}{l}
a_{\mathrm{m}} \\
b_{\mathrm{m}} \\
c_{\mathrm{m}}
\end{array}\right)=\left(\begin{array}{llr}
0.5 & -0.5 & 0 \\
0 & 0 & -1 \\
0.5 & 0.5 & 0
\end{array}\right)\left(\begin{array}{l}
a_{\mathrm{o}} \\
b_{\mathrm{o}} \\
c_{\mathrm{o}}
\end{array}\right)
$$

and

$$
\left(\begin{array}{l}
a_{\mathrm{o}} \\
b_{\mathrm{o}} \\
c_{\mathrm{o}}
\end{array}\right)=\left(\begin{array}{rrr}
1 & 0 & 1 \\
-1 & 0 & 1 \\
0 & -1 & 0
\end{array}\right)\left(\begin{array}{l}
a_{\mathrm{m}} \\
b_{\mathrm{m}} \\
c_{\mathrm{m}}
\end{array}\right)
$$




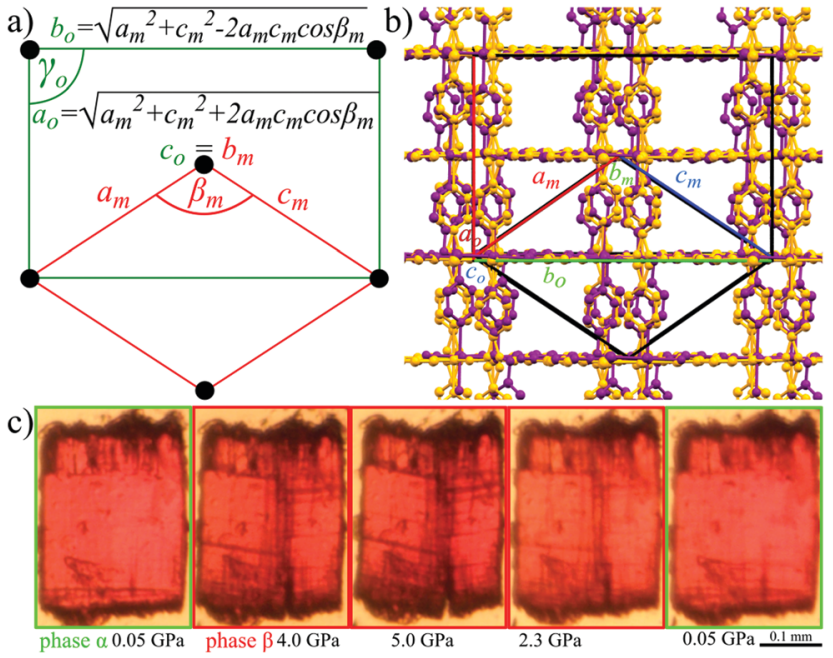

Fig. 6 (a) Lattice relations between the prototypic orthorhombic phase $\alpha$ (green) and monoclinic orientational state (red) in ferroelastic crystal AMU3. (b) Orthorhombic (yellow) and monoclinic (purple) AMU3 structures (measured at $0.1 \mathrm{MPa}$ and $1.27 \mathrm{GPa}$, respectively), compared by overlaying their ball-and-stick drawings. Indexes ' $O$ ' and ' $m$ ' refer to phases $\alpha$ and $\beta$, respectively. (c) Photographs of a sample crystal with defects appearing in the compressed $\beta$ phase along planes (100)。 and (010), and the cleavage of the crystal along (010)。 (cf. Movie S1, ESI†).

Thus the monoclinic strain $\eta^{\prime}$ of phase $\beta$ can be measured as the distortion of angle $\gamma_{\mathrm{o}}$ from $90^{\circ}$

$$
\eta^{\prime}= \pm\left(\gamma_{0}-90^{\circ}\right)
$$

where signs plus and minus correspond to two possible ferroelastic orientational states, $\gamma_{\mathrm{o}}=\cos ^{-1}\left\{\left(a_{\mathrm{m}}^{2}-c_{\mathrm{m}}{ }^{2}\right) /\left(a_{\mathrm{o}} \cdot b_{\mathrm{o}}\right)\right\}$, $a_{\mathrm{o}}=\left(a_{\mathrm{m}}^{2}+c_{\mathrm{m}}^{2}+2 a_{\mathrm{m}} c_{\mathrm{m}} \cos \beta_{\mathrm{m}}\right)^{1 / 2} \quad$ and $\quad b_{\mathrm{o}}=\left(a_{\mathrm{m}}{ }^{2}+c_{\mathrm{m}}{ }^{2}-\right.$ $\left.2 a_{\mathrm{m}} c_{\mathrm{m}} \cos \beta_{\mathrm{m}}\right)^{1 / 2}$. It is also possible to choose the order parameter $\eta^{\prime \prime}$ of this ferroelastic as a difference between the primitive cell parameters: $\eta^{\prime \prime}= \pm\left(a_{\mathrm{m}}-c_{\mathrm{m}}\right)$, or the relevant diagonals of the $C$-lattice cell.

\section{Crystal damage and self-healing}

The lattice strain described above results in the cleavage of the crystal samples. The cleavage occurs at about $3 \mathrm{GPa}$, i.e. well above the phase transition when the shear strain $\eta^{\prime}$ increases to about $5^{\circ}$ (the inset in Fig. 4), and so the angle between the cleaved planes becomes circa $10^{\circ}$ (Fig. 2). It appears that between 0.4 and 2.0 GPa (for the AMU3·DMF sample compressed in methanol:ethanol:water) the shear strain is partly accommodated by the elasticity of the crystal, and also by micro fractures, which produces a greenish tint of the scattered light (Fig. 2), or as plane defects clearly visible as thin lines in Movie S1 (see the ESI $\dagger$ ). It is apparent from the pleochroic colours that the domain walls are formed along crystal planes $(010)_{\mathrm{o}}$ and/or $(100)_{\mathrm{o}}$. The directions of defects can be easily identified according to the pleochroic colours (cf. Movie S1, ESI $\dagger$ ). These domain walls along $(010)_{\mathrm{o}}$ and $(100)_{\mathrm{o}}$ are present in the sample shown in Fig. 6c. The orientation of the domain walls illustrate the monoclinic strain building up in the sample crystal and that it breaks just along one of the planes, which is sufficient for releasing the strain. Movie S1 (ESI $\dagger$ ) shows that the large fractures formed above 3.0 GPa almost completely disappear for reiterated cycles of increased and decreased pressure. Such a self-healing property is sought for its practical applications. ${ }^{62,79-81}$ The structural mechanism revealed for the AMU3 crystals, and in particular the rotations and tilts of the linkers as well as their conformational distortions, can be used for designing new self-healing materials.

\section{Strain-structure coupling}

As described above, the $\eta^{\prime}$ strain originates from the AZPY linkers and their $\mathrm{N}-\mathrm{Cd}$ coordination bonds. The tilts of the AZPY molecules are consistent in shifting the CdBDC sheets along axis $b_{\mathrm{O}}$. The order and disorder of the AZPY linkers in phases $\alpha$ and $\beta$ have some effects on their sorption properties. The shear strain folds the framework and in this way the voids are reduced in volume (Fig. 7). The disordered AZPY linkers occupy more space, so the disorder elimination in phase $\beta$ increases the space available for guests, but at still higher pressure the shear strain is to some extent limited by the framework stiffness. After the disorder elimination a further volume reduction of the voids is achieved through the conformational twisting of the AZPY molecules. We have found that these transformations depend on the guest and are sensitive to the crystal environment. The guests clearly affect the unit-cell dimensions and their compression, as shown in Fig. S3 in the ESI. $\dagger$ The disorder persists even at the liquidnitrogen temperature, whereas it is efficiently eliminated at a fraction of one GPa. Thus the AZPY linkers can be used for designing the elastic properties of MOF crystals, and making

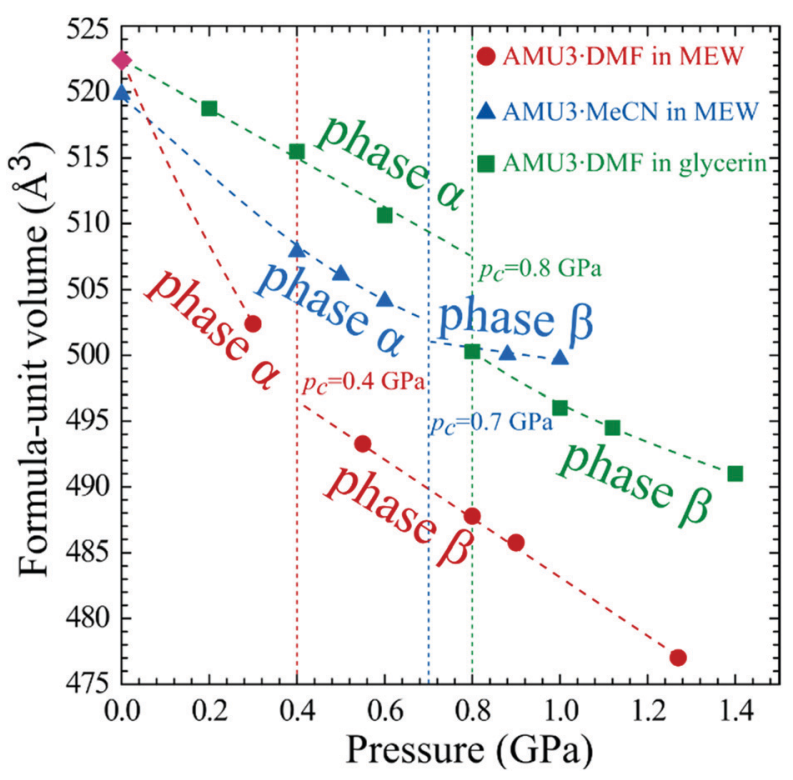

Fig. 7 Formula-unit volume for AMU3.DMF compressed in methanol: ethanol: water 16:3:1 mixture (MEW, red circles), AMU3.MeCN (acetonitrile) in MEW (blue triangles), and with DMF as a guest molecule compressed in glycerin (green squares). The ESDs are smaller than the plotted symbols. 
them sensitive to chemical and mechanical stimuli, which can change their sorption and breathing properties. Fig. S6 (ESI $\dagger$ ) shows that a considerable number of crystals containing AZPY molecules is disordered. It indicates that the pressure-induced transformations analogous to those in AMU3 may concern also other compounds.

It should be noted that the AMU3 crystals strongly change their volume under pressure and that this effect depends both on the guest molecules and on the PTM (Fig. 7 and Tables S1S6, ESI $\dagger$ ). The compression of phase $\alpha$-AMU3.DMF compressed in MEW is over three times stronger compared to that of $\alpha$-AMU3.DMF compressed in glycerin. Surprisingly, the largest volume change is observed for AMU3.DMF compressed in MEW, which in principle should allow the water and methanol molecules to penetrate easily into the pores, while the compression of AMU3.DMF in glycerin is least responsive to pressure. We have connected the observed compressibility differences with large voids in the AMU3 structure, and with the ability of the crystals to extrude the DMF molecules. This extrusion requires the presence of the MEW mixture, possibly because of the substitution of the DMF guests with much smaller water and methanol molecules from the crystal environment. Such an exchange is not possible for significantly more viscous glycerin liquid and with molecules much larger than the MEW components. The strong compression of $\alpha$-AMU3. DMF is most likely caused by the altered contents of the voids. This reasoning is consistent with the transition pressure of $\alpha$-AMU3. DMF compressed in MEW being lower than that of $\alpha$-AMU3.DMF compressed in glycerin. The crystal with smaller guests or with partly filled voids can be expected to transform to the $\beta$ phase at a lower pressure than that with the filled voids, and hence are better supported from inside and less prone to collapse. ${ }^{82}$ The volume reduction of $\alpha$-AMU3 MeCN compressed in MEW is intermediate between those of $\alpha$-AMU3.DMF compressed in glycerin and in MEW, which strongly suggests that the contents of voids in $\alpha$-AMU3.DMF compressed in MEW is reduced. All these observations indicate that the large volume reduction of $\alpha$-AMU3.DMF compressed in MEW cannot be regarded as compressibility in the physical sense, but that it is connected to the reduced composition of the crystal.

\section{Pleochroism of AMU3}

Phase $\alpha$-AMU3 has the structural property that all AZPY linkers are aligned parallel in the crystal structure, and all BDC linkers are perpendicular to this direction. Consequently, the optical properties of AMU3 crystals are strongly anisotropic, which leads to their strong pleochroism. The crystals are either transparent or red, as shown in Fig. 1 and Fig. S8 (ESI $\dagger$ ). In phase $\beta$ their perpendicular positions are off-set by a few degrees only, and the strong pleochroism remains.

\section{Conclusions}

Pleochroic crystals of AMU3 display several features attractive for sensor applications, as they are prone to the guest exchange, but are hardly affected by temperature and only the pressure leads to the ferroelastic strain. The crystals exhibit self-healing properties, which repair the damage induced by the phase transition to the ferroelastic orientational states. This type of damage disqualifies many ferroelastic materials from practical applications. We have shown that the interplay of the framework topology with the flexibility of linkers can lead to specific types of structural transformations of MOFs. In AMU3 the rigid sheets of Cd(II)-BDC contrast with the AZPY linkers disordered in two orientations. The disorder is coupled to the lattice strain and is sensitive to the guest types and to the crystal environment, which can be applied in chemo-mechanical transducers in sensors. The survey of MOFs involving AZPY linkers reveals a considerable number of similarly disordered structures (76 out of 173), which can display analogous properties. Furthermore, the number of disordered azopyridine linkers in any kind of compound is similarly high: there are 466 structures with the 'disorder' descriptor in the CCDC version 2020.0, and some properties of AMU3 can be applicable to those structures, too. These numbers show that the possible disorder and conformational properties of AZPY molecules can be considered when designing the structures of MOFs aimed at specific properties and applications.

\section{Conflicts of interest}

There are no conflicts to declare.

\section{Acknowledgements}

Authors are grateful to Dr Szymon Sobczak for his advice and helpful comments. This research was supported by funding from the Polish National Science Centre: OPUS 10 No. UMO2015/19/B/ST5/00262; PRELUDIUM 18 No. UMO-2019/35/N/ ST5/01838 and grant POWR.03.02.00-00-I026/16 co-financed by the EU European Social Fund under the Operational Program Knowledge Education Development.

\section{Notes and references}

1 H. C. Zhou, J. R. Long and O. M. Yaghi, Chem. Rev., 2012, 112, 673-674.

2 J. Liu, D. Zhu, C. Guo, A. Vasileff and S. Qiao, Adv. Energy Mater., 2017, 1700518, 1-26.

3 D. Zhao, D. J. Timmons, D. Yuan and H.-C. Zhou, Acc. Chem. Res., 2011, 44, 123-133.

4 N. Novendra, J. M. Marrett, A. D. Katsenis, H. M. Titi, M. Arhangelskis, T. Friščić and A. Navrotsky, J. Am. Chem. Soc., 2020, 142, 21720-21729.

5 J. E. Mondloch, O. Karagiaridi, O. K. Farha and J. T. Hupp, CrystEngComm, 2013, 15, 9258-9264.

6 K. A. Zenere, S. G. Duyker, E. Trzop, E. Collet, B. Chan, P. W. Doheny, C. J. Kepert and S. M. Neville, Chem. Sci., 2018, 9, 5623-5629.

7 H. Li, M. Eddaoudi, M. O'Keeffe and O. M. Yaghi, Nature, 1999, 402, 276-279. 
8 H. J. Park, D. Lim, W. S. Yang, T. Oh and M. P. Suh, Chem. Eur. J., 2011, 17, 7251-7260.

9 J. Sotelo, C. H. Woodall, D. R. Allan, E. Gregoryanz, R. T. Howie, K. V. Kamenev, M. R. Probert, P. A. Wright and S. A. Moggach, Angew. Chem., 2015, 127, 13530-13534.

10 G. Sezer, M. Arici, İ. Erucar, O. Z. Yeşilel, H. U. Özel, B. T. Gemici and H. Erer, J. Solid State Chem., 2017, 255, 89-96.

11 A. M. Ako, C. S. Hawes, B. Twamley and W. Schmitt, CrystEngComm, 2017, 19, 994-1000.

12 R. Haldar, S. Bonakala, P. Kanoo, S. Balasubramanian and T. K. Maji, CrystEngComm, 2014, 16, 4877-4885.

13 S. Noro, M. Kondo, T. Ishii, S. Kitagawa and H. Matsuzaka, J. Chem. Soc., Dalton Trans., 1999, 1569-1574.

14 G. J. Halder and C. J. Kepert, Aust. J. Chem., 2005, 58, 311-314.

15 S. Sanram, J. Boonmak and S. Youngme, Inorg. Chim. Acta, 2018, 469, 11-19.

16 A. Vlad, M. Cazacu, M. Zaltariov, A. Bargan, S. Shova and C. Turta, J. Mol. Struct., 2014, 1060, 94-101.

17 R. Kumar, K. Jayaramulu, T. K. Maji and C. N. R. Rao, Dalton Trans., 2014, 43, 7383-7386.

18 G. Günay, O. Z. Yesilel, H. Erer, S. Keskin and A. Tabak, Polyhedron, 2015, 100, 108-113.

19 Y. Chen, H. Yu, M. Quan, L. Zhang, H. Yang and Y. Lu, RSC $A d v .$, 2015, 5, 4675-4680.

20 K. Aoki, M. Nakagawa and K. Ichimura, J. Am. Chem. Soc., 2000, 122, 10997-11004.

21 C. Bin Fan, Z. Q. Liu, L. Le Gong, A. M. Zheng, L. Zhang, C. S. Yan, H. Q. Wu, X. F. Feng and F. Luo, Chem. Commun., 2017, 53, 763-766.

22 Z.-J. Lin, T.-F. Liu, B. Xu, L.-W. Han, Y.-B. Huang and R. Cao, CrystEngComm, 2011, 13, 3321-3324.

23 P. Kanoo, A. C. Ghosh, S. T. Cyriac and T. Kumar, Chem. Eur. J., 2012, 18, 237-244.

24 I. E. Collings and A. L. Goodwin, J. Appl. Phys., 2019, 126, 1-13.

25 A. J. Graham, D. R. Allan, A. Muszkiewicz, C. A. Morrison and S. A. Moggach, Angew. Chem., Int. Ed., 2011, 50, 11138-11141.

26 S. A. Moggach, T. D. Bennett and A. K. Cheetham, Angew. Chem., Int. Ed., 2009, 48, 7087-7089.

27 S. C. Mckellar and S. A. Moggach, Acta Crystallogr., 2015, B71, 587-607.

28 J. Navarro-Sánchez, I. Mullor-Ruíz, C. Popescu, D. Santamaría-Pérez, A. Segura, D. Errandonea, J. González-Platas and C. Martí-Gastaldo, Dalton Trans., 2018, 47, 10654-10659.

29 A. Celeste, A. Paolone, J. Itie, F. Borondics, B. Joseph, O. Grad, G. Blanita, C. Zlotea and F. Capitani, J. Am. Chem. Soc., 2020, 140, 15012-15019.

30 E. V. Boldyreva, J. Mol. Struct., 2003, 647, 159-179.

31 V. S. Minkov, N. A. Tumanov, R. Q. Cabrera and E. V. Boldyreva, CrystEngComm, 2010, 12, 2551-2560.

32 R. Lee, J. A. K. Howard, M. R. Probert and J. W. Steed, Chem. Soc. Rev., 2014, 43, 4300-4311.

33 R. H. Baughman, R. H. Baughman and S. Stafstro, Science, 1998, 279, 1522.
34 I. D. H. Oswald and C. M. Beavers, CrystEngComm, 2019, 21, 4420-4421.

35 A. B. Cairns and A. L. Goodwin, Phys. Chem. Chem. Phys., 2015, 17, 20449-20465.

36 W. Cai and A. Katrusiak, Nat. Commun., 2014, 5, 1-8.

37 Z. Chen, B. Xu, Q. Li, Y. Meng, Z. Quan and B. Zou, Inorg. Chem., 2020, 59, 1715-1722.

38 J. Binns, K. V. Kamenev, K. E. R. Marriott, G. J. McIntyre, S. A. Moggach, M. Murrie and S. Parsons, Chem. Commun., 2016, 52, 7486-7489.

39 W. Li, M. R. Probert, M. Kosa, T. D. Bennett, A. Thirumurugan, R. P. Burwood, M. Parinello, J. A. K. Howard and A. K. Cheetham, J. Am. Chem. Soc., 2012, 134, 11940-11943.

40 W. Cai, A. Gładysiak, M. Anioła, V. J. Smith, L. J. Barbour and A. Katrusiak, J. Am. Chem. Soc., 2015, 137, 9296-9301.

41 S. A. Hodgson, J. Adamson, S. J. Hunt, M. J. Cliffe, A. B. Cairns, A. L. Thompson, M. G. Tucker, N. P. Funnell and A. L. Goodwin, Chem. Commun., 2014, 50, 5264-5266.

42 T. Lim, Phys. Status Solidi B, 2017, 1600682, 1-11.

43 G. Feng, W. X. Zhang, L. Dong, W. Li, W. Cai, W. Wei, L. Ji, Z. Lin and P. Lu, Chem. Sci., 2019, 10, 1309-1315.

44 S. Sobczak, A. Półrolniczak, P. Ratajczyk, W. Cai, A. Gładysiak, V. I. Nikolayenko, D. C. Castell, L. J. Barbour and A. Katrusiak, Chem. Commun., 2020, 56, 4324-4327.

45 D. Fairen-Jimenez, S. A. Moggach, M. T. Wharmby, P. A. Wright, S. Parsons and T. Düren, J. Am. Chem. Soc., 2011, 133, 8900-8902.

46 S. C. McKellar, J. Sotelo, A. Greenaway, J. P. S. Mowat, O. Kvam, C. A. Morrison, P. A. Wright and S. A. Moggach, Chem. Mater., 2016, 28, 466-473.

47 N. Nijem, P. Canepa, U. Kaipa, K. Tan, K. Roodenko, S. Tekarli, J. Halbert, I. W. H. Oswald, R. K. Arvapally, C. Yang, T. Thonhauser, M. A. Omary and Y. J. Chabal, J. Am. Chem. Soc., 2013, 135, 12615-12626.

48 P. Z. Moghadam, J. F. Ivy, R. K. Arvapally, A. M. Dos Santos, J. C. Pearson, L. Zhang, E. Tylianakis, P. Ghosh, I. W. H. Oswald, U. Kaipa, X. Wang, A. K. Wilson, R. Q. Snurr and M. A. Omary, Chem. Sci., 2017, 8, 3989-4000. 49 S. Sobczak and A. Katrusiak, Cryst. Growth Des., 2018, 18, 1082-1089.

50 G. J. Halder, C. J. Kepert, B. Moubaraki, K. S. Murray and J. D. Cashion, Science, 2002, 298, 1762-1765.

51 P. D. Southon, L. Liu, E. A. Fellows, D. J. Price, G. J. Halder, K. W. Chapman, B. Moubaraki, K. S. Murray, J. F. Létard and C. J. Kepert, J. Am. Chem. Soc., 2009, 131, 10998-11009.

52 M. Fisch, A. Lanza, E. Boldyreva, P. Macchi and N. Casati, J. Phys. Chem. C, 2015, 119, 18611-18617.

53 B. A. Zakharov and E. V. Boldyreva, CrystEngComm, 2019, 21, 10-22.

54 A. Półrolniczak, S. Sobczak and A. Katrusiak, Inorg. Chem., 2018, 57, 8942-8950.

55 S. Sobczak and A. Katrusiak, Inorg. Chem., 2019, 58, 11773-11781. 56 S. Sobczak, W. Drożdż, G. Lampronti, A. Belenguer, A. Katrusiak and A. R. Stefankiewicz, Chem. - Eur. J., 2018, 24, 8769-8773. 
57 A. Lanza, L. S. Germann, M. Fisch, N. Casati and P. Macchi, J. Am. Chem. Soc., 2015, 137, 13072-13078.

58 E. C. Spencer, M. S. R. N. Kiran, W. Li, U. Ramamurty, N. L. Ross and A. K. Cheetham, Angew. Chem., Int. Ed., 2014, 53, 5583-5586.

59 M. Andrzejewski and A. Katrusiak, J. Phys. Chem. Lett., 2017, 8, 279-284.

60 D. R. Allan, A. J. Blake, D. Huang, T. J. Prior and M. Schröder, Chem. Commun., 2006, 4081-4083.

61 J. A. Gould, M. J. Rosseinsky and S. A. Moggach, Dalton Trans., 2012, 41, 5464-5467.

62 R. P. Wool, Soft Matter, 2008, 4, 400-418.

63 P. Naumov, S. Chizhik, P. Commins and E. Boldyreva, in Mechanically Responsive Materials for Soft Robotics, ed. H. Koshima, Wiley-VCH Verlag GmbH\& Co. KGaA, 1st edn, 2020, pp. 105-137.

64 D. Kim, D. R. Whang and S. Y. Park, J. Am. Chem. Soc., 2016, 138, 8698-8701.

65 L. Feng, J. L. Li, G. S. Day, X. L. Lv and H. C. Zhou, Chem, 2019, 5, 1265-1274.

66 Y. Yang, X. Ding and M. W. Urban, Prog. Polym. Sci., 2015, 49-50, 34-59.

67 P. Kumar, B. Anand, Y. F. Tsang, K. H. Kim, S. Khullar and B. Wang, Environ. Res., 2019, 176, 108488.

68 A. Katrusiak, International Tables for Crystallography, vol. H, ch. 2.7, 2019, pp. 156-173.

69 L. Merrill and W. A. Bassett, Rev. Sci. Instrum., 1974, 45, 290-294.
70 H. K. Mao, J. Xu and P. M. Bell, J. Geophys. Res., 1986, 91, 4673.

71 G. J. Piermarini, S. Block, J. D. Barnett and R. A. Forman, J. Appl. Phys., 1975, 46, 2774-2780.

72 A. Budzianowski and A. Katrusiak, High-Pressure Crystallography, Kluwer Acad. Publ. Dordrecht, Netherlands, 2004, pp. 101-112.

73 Agilent, Technol. UK Ltd, Yarnton, Oxford, UK.

74 O. V. Dolomanov, L. J. Bourhis, R. J. Gildea, J. A. K. Howard and H. Puschmann, J. Appl. Crystallogr., 2009, 42, 339-341.

75 G. M. Sheldrick, Acta Crystallogr., Sect. A: Found. Crystallogr., 2008, 64, 112-122.

76 G. M. Sheldrick, Acta Crystallogr., Sect. C: Cryst. Struct. Commun., 2015, 71, 3-8.

77 A. Katrusiak, REDSHABS - Program for correcting reflections intensities for DAC absorption, gasket shadowing and sample-crystal absorption, Adam Mickiewicz University, Poznan, Poland, 2003.

78 A. Katrusiak, Zeitschrift fur Krist., 2004, 219, 461-467.

79 G. Wypych, Self-Healing materials: Principles and technology, ChemTec Publishing, 1st edn, 2017.

80 M. D. Hager, S. van der Zwaag and U. S. Schubert, Selfhealing Materials, Springer International Publishing, 1st edn, 2016.

81 S. K. Ghosh, Self-healing Materials: Fundamentals, Design Strategies, and Applications, Wiley-VCH, 2008.

82 F.-X. Coudert, Chem. Mater., 2015, 27, 1905-1916. 